\title{
Beaten ballots: political participation dynamics amidst police interventions
}

\author{
Toni Rodon* (D) and Marc Guinjoan (C) \\ Department of Political and Social Sciences, Universitat Pompeu Fabra, Barcelona, Spain and Institutions and Political \\ Economy Research Group (IPErG). Universitat de Barcelona. ${ }^{\dagger}$ \\ ${ }^{*}$ Corresponding author. Email: toni.rodon@upf.edu
}

(Received 16 May 2019; revised 13 April 2020; accepted 22 April 2020; first published online 7 January 2021)

\begin{abstract}
What is the effect of violence on political mobilization? Taking the repression-mobilization nexus debate as a starting point, we study the effects of police interventions on political participation, focusing on the Spanish police crackdown on Catalonia's independence referendum on 1 October 2017. We analyze the effect of police actions on turnout using detailed aggregate data, as well as a survey conducted a few days after the referendum. The two empirical approaches show that police interventions had both deterrent and inverse spatial spillover effects. Although police raids had a local negative impact on turnout, they induced positive spillover effects in the surrounding areas. Our findings also indicate heterogeneity in the spatial dynamics, with police actions encouraging people to go to vote in nearby areas, but also mobilizing residents in neighboring areas to participate, especially those individuals with fewer incentives to turn out to vote.
\end{abstract}

Keywords: Civil/domestic conflict; ethnicity and nationalism; political participation and turnout; voting behavior

\section{Introduction}

The effect of state violence on political mobilization remains an open question. The literature on the relationship between state-prompted violence and political behavior has generally focused on violent clashes against demonstrators or social movements, events that are infrequent or normally occur on a single specific location. Crucially, and despite much ink has been spilled as to why and how state violence should affect political mobilization, most studies still revolve around two different theoretical expectations. The first strand suggests that violence quells collective action and diminishes political participation. The second strand of the literature argues that violence can backfire and ultimately stimulate political mobilization. In parallel, the literature has also discussed the existence of a U-shaped pattern between violence and mobilization, but most studies think of this relationship in temporal terms. In contrast, there are not many studies focusing on the type of relationship between violence and subsequent mobilization from a spatial point of view. Although there are reasons to believe that the effect of violence is the same locally than in neighboring areas, it can also be argued that the effect of violence on mobilization is amplified in spatially close areas. Taking these gaps into account, this paper aims at making a contribution to the literature of state violence and political mobilization. By focusing on the state-sanctioned police interventions perpetrated against the 2017 Catalan referendum on independence, we study whether electoral participation was significantly affected by police interventions, the dynamics of

\footnotetext{
${ }^{\dagger}$ The original version of this article was published with incorrect an author affiliation. A notice detailing this has been published and the errors rectified in the online PDF and HTML version.

(C) The Author(s), 2021. Published by Cambridge University Press on behalf of the European Political Science Association. This is an Open Access article, distributed under the terms of the Creative Commons Attribution licence (http://creativecommons.org/licenses/by/4.0/), which permits unrestricted re-use, distribution, and reproduction in any medium, provided the original work is properly cited.
} 
this relationship over space and who was more likely to be (de)mobilized. More specifically, our contribution is threefold:

First, we complement the literature on the effects of police actions on political mobilization in democracies. As mentioned, scholars have long examined whether state violence quells political mobilization or whether it can backfire and stimulate protest. Most contributions, however, come from non-democratic systems, where repression does not only take place during the election day but is a constant feature of the political system. This for instance led Aytaç et al. $(2017,1)$ to argue that "backlash mobilization [as a result of violence] may be less germane in democracies." Despite in the 2017 referendum on Catalan independence both the occurrence and intensity of violence was unprecedented, many contemporary democracies coexist with violent events (Muñoz and Anduiza, 2019; Kriesi et al., 2020), the consequences of which remain largely understudied.

Second, previous studies debate whether the relationship between repression and subsequent mobilization follows a U-curve, an inverted U-curve or, more in general, whether the deterrent and radicalizing effects both occur and/or trade off over time (Francisco, 1995). We complement this debate by examining a similar but largely ignored relationship in the mobilization literature, that is, the spatial dynamics triggered by violence on political mobilization. In other words, do we observe a positive/negative effect of violence on political participation only in places where it occurred? Or do people also react to violent events in the surrounding areas?

Finally, from an individual point of view, the scholarly literature has recently devoted much effort to understand who reacts to the actions perpetrated by the police-see, for instance, Aytaç, Schiumerini, and Stokes (2017) or Enos, Kaufman, and Sands (2019). By studying the Catalan case, we complement this literature by analyzing a context in which political competition is polarized along national identity lines and, therefore, it is a priori unclear who gets mobilized.

Our empirical analysis makes use of detailed geographic information on police raids and a survey that includes information on the geo-coordinates of each respondent's address. After showing that police interventions followed a quasi-random pattern, our findings show that police violence decreased political participation locally, but induced mobilization in the immediate surrounding areas. In addition, we show that this pattern was especially prevalent among those individuals with a dual Catalan and Spanish identity, whose initial predisposition to vote in the referendum was low.

\section{Theoretical arguments: violence and political mobilization}

Does state-prompted violence have an effect on political mobilization? And, if so, does it decrease mobilization or increase it? Academic research has long been preoccupied with understanding the effects of violence on political behavior, a debate that is often referred to as the repression-dissent nexus or the repression-mobilization puzzle (Lichbach, 1987; Earl, 2011).

The first theoretical perspective contends that state violence and/or repression quells political, and collective action. As a result of the socio-psychological consequences of violence (i.e., fear or risk-aversion) (Salamon and Van Evera, 1973), the targeted group might become discouraged and withdraw from political activism. Similarly, the rational perspective argues that violence increases the costs of collective action and therefore has a negative impact on the level of political mobilization (Muller and Weede, 1990). Several findings are in line with the deterrence logic. For instance, in the context of Mexico, Ukraine, and Afghanistan, respectively, Ley (2017), Coupe and Obrizan (2016), and Condra et al. (2018) show that state violence depresses electoral participation. Similarly, Jones et al. (2017) find that lynching in the USA reduced local black voter turnout, and Linden et al. (2006) conclude that repression to extreme-right activism in the Netherlands let to political disengagement.

The second theoretical approach stands at the opposite side and argues that state violence can backfire and stimulate political mobilization. The basic tenet of this model is that state violence reveals new information about the regime and its opponents and further intensifies the frustrations underlying citizens' protests, which contributes to its escalation (Gurr, 1969; Rasler, 1996). In other words, violence might give incentives to core opposition supporters to increase their 
mobilization efforts or even convince bystanders or undecided to join the protest activities (Chenoweth and Stephan, 2011). Previous studies also provide evidence supporting the backfire logic. Wilkinson (2006) shows that violence encouraged by Indian elites increased turnout among their supporters, whereas Blattman (2009) finds that violence in Uganda led to a higher involvement in political activities. This backfire effect is not circumscribed to developing economies. Recently, Enos, Kaufman, and Sands (2019) have found that, as a result of the 1992 Los Angeles riots, violent political protests crucially spurred political participation among people who shared an identity with the rioters. Additionally, Aytaç, Schiumerini, and Stokes (2017) have shown that police violence has a mobilizing effect, even among citizens who are ideologically away from protesters. Finally, Muñoz and Anduiza (2019) show that people react differently to violence as a function of their ideological predisposition: it strengthens the view of those that stand at the opposite ideological side of the protester's goals, but it also has an effect on weak supporters or non-aligned citizens.

The debate about the consequences of State violence on political mobilization is especially intense in the literature that examines the effect of police violence on people's attitudes and behavior. This literature, particularly prominent in the USA, mirrors the debate presented above and offers once again a dual picture. On the one hand, some studies show that violent police actions decrease an individual's contact with the government and/or dampens other forms of political engagement (Lerman and Weaver, 2014; Desmond et al., 2016; Laniyonu, 2019). On the other, there is alternative evidence showing that policing may backfire and trigger a wave of political protests (Martin, 2005), when individuals react with outrage to events that they perceive as unjust (Hess and Martin, 2006).

This (non-settled) debate is intertwined with a related one, namely the specific type of relationship between repression and subsequent mobilization. Classical studies argue that responses to repression follow an inverted U-curve (Rasler, 1996; Lichbach and Gurr, 1981; Muller and Weede, 1990), that is, protest mobilization increases with repression, but it decreases over time (DeNardo, 2014). However, the type of relationship between state repression and the spatial dynamics of political mobilization has received far less attention. The literature on social conflict emphasizes the role played by contagion, bandwagon effects, and information cascades in mobilizing people (Rasler, 1996). The crucial point of these studies is that an individual's probability to participate depends critically on how many other individuals participate. The classical study by Granovetter (1978) explains that an individual's decision to participate can potentially push others over their own individual-specific thresholds, triggering what the literature calls a bandwagon effect or an information cascade. This spatial contagion effect has been shown by some studies. For instance, Baudains, Johnson, and Braithwaite (2013) find strong evidence of contagion in the 2011 London riots, whereby violence spread in a contiguous ways from one area to the next. Similarly, and focusing on the UK's Swing riots of 1830-31, Aidt, Leon, and Satchel (2017) conclude that spatial contagion is a powerful force driving mobilization. If we accept the spatial perspective and consider that state violence triggers political mobilization in surrounding areas, one can also theoretically incorporate the idea of an inverted U-shape relationship. In other words, once neighboring citizens perceive that police interventions are taking place next door, violence can backfire and stimulate mobilization in the surrounding areas and do it a higher degree than places located further away. This behavior not only hinges on the idea that people in neighboring areas are more likely to expect a police intervention, but on several other factors. More concretely, citizens in neighboring towns are more likely to know people directly affected by a police intervention, their social network-and hence the flow of information-is likely to be tighter, and the affective connection to a place they know or have probably visited in the past is likely to be higher. Consequently, the anger likely spurred by police violence is expected to be stronger where a police intervention took place or in the surrounding areas. ${ }^{1}$

\footnotetext{
${ }^{1}$ Anger is a crucial psychological trait that motivates a person to take action against the responsible agent and boosts political mobilization (Valentino et al., 2011).
} 


\section{The Catalan case: support for secession and the role of identity}

\subsection{The 2017 referendum on secession}

In this paper, we examine the effect on political mobilization of the state-sanctioned police interventions perpetrated against the Catalan referendum on independence that took place on the 1 October 2017. We next succinctly contextualize our case of study.

Since 2012, the Catalan government has sought to agree with the Spanish executive on the celebration of a referendum on secession. Despite various attempts, the response from the central government has invariably been to reject them. In parallel, the Catalan government has attempted to circumvent the veto through alternative means. On 9 November 2014, the Catalan executive organized a "Popular Consultation," but prohibition from the Spanish Constitutional Court forced the Catalan government to turn it into a "Citizen participation process." The impossibility to hold a legal referendum encouraged the Catalan executive to call for early regional election in September 2015, which was announced as a plebiscite for independence. Within the secessionist camp, the purported goal of the election was to obtain a majority of seats in the Catalan parliament and proclaim independence within the following 18 months. Finally, the pro-secession parties gained 72 out of 135 seats in the Parliament but fell short of achieving a majority of the votes (47.7 percent).

Soon after the elections took place, pro-independence politicians expressed the need to hold a new and definitive referendum on secession, irrespective of the central government's approval. In September 2016, the Catalan government announced that a new referendum would be held within the following year. Despite the proposition immediately faced the opposition of the Spanish government and the main Spanish parties, the referendum was finally announced on Sunday 1 October 2017. The preparation of the referendum entailed a series of legal arrangements such as an electoral commission, a census, polling stations, etc. However, when the law of the referendum was passed in the Catalan Parliament in early September 2017, the Spanish Constitutional Court soon declared it unconstitutional. Thereafter, the electoral commission was dismantled, the census register was not sent to voters in advance at home, the system of voting by post was shut down and, to prevent the celebration of the referendum, in late September 2017 the Spanish government deployed more than 10,000 police officers in Catalonia, most of them coming from other Spanish regions. All in all, the Catalan government stood firm in the determination to hold the referendum.

Given the Constitutional Court's mandate to police to seal-off and prevent anyone from entering polling stations (mainly schools) on Sunday 1 October, two days before the referendum polling stations were occupied by individuals-mostly coordinated by Parents' Associations-in order to ensure that these could open on the referendum day. On 1 October, only a few minutes before the vote began, the Catalan executive announced that a universal census would be established so that citizens who wished to vote in the referendum could do so at any polling station in the region. The goal was to ensure that, if voting locations were eventually closed by the police, voters could go to another polling station and cast their ballot. In the early morning of the 1 October, Spanish police squads were sent to several locations to stop the referendum. Finally, in many polling stations, the police attempts to halt the vote exploded into violence. Riot squads pushed their way through crowds of would-be voters to access some of the polling stations, using batons, rubber bullets, and tear gas canisters. More than a thousand people were injured. ${ }^{3}$

\footnotetext{
${ }^{2}$ More information on the 9 November consultation can be found in the online Appendix, section D. We use data from this consultation in some robustness checks.

${ }^{3}$ Source: Catalan Health Service from the Generalitat de Catalunya. Available at http://premsa.gencat.cat/pres_fsvp/docs/ 2017/10/20/11/15/232799c8-755f-4810-ba56-0a5bbb78609c.pdfpremsa.gencat.cat (last accessed: 28 November 2018). Such a violent crackdown by the Spanish police was not expected. This implies that voters did not foresee violent events and, therefore, could not adapt their behavior ahead of time. This assumption is explored in more detail in the online Appendix, section I.
} 
Finally, two important things are worth mentioning:

First, although the referendum was designed to work as an official consultation, it faced strong opposition from most Spain-wide parties in Catalonia. These parties encouraged their supporters to boycott it. In the end, 2.29 million votes were counted (41.2 percent of the census), 90.2 percent of which were Yes votes, 7.8 percent No votes, and 2 percent blank votes). Overall, the perception of the meaning of the 1 October referendum varies across individuals: whereas some considered it was a real referendum on independence, others saw it as an act of protest or civil disobedience or as an illegal act. As we will see below, these different ways of seeing the 1 October referendum were essentially shaped by an individual's national identity, a crucial factor that shapes political behavior in the region.

Second, the images of police violence quickly spread over the (social) media, which constitutes a violation of the Stable Unit Treatment Value Assumption (SUTVA). In other words, a lot of people were exposed to the police violence, even citizens living in municipalities where the police did not intervene. Yet, we believe SUTVA is not crucially affecting our story. From a theoretical point of view, and precisely for the reasons developed above, such as the tight spatially close networks, the flow of information was unlikely to be similar near affected/unaffected municipalities. But, even if we assume it was the same, it is reasonable to think that the effect it triggered was larger where it occurred or in nearby places. Realizing that a police intervention took place next door, knowing a relative that witnessed it or was affected by is arguably not the same than watching police interventions in a distant municipality or on TV/Twitter. In addition, from an empirical point of view, the existence of SUTVA goes against our alternative hypothesis, as it decreases the likelihood of not rejecting our null hypothesis-no relationship between policing and political mobilization-and, if anything, underestimates our results.

\subsection{The correlates of support for secession}

When assessing support for secession in regions such as Catalonia, the general claim in the literature is that national identity plays a crucial role: the higher an individual feels attached to the region (as compared to the nation), the more likely is that he/she supports secession. Previous studies have confirmed this logic and found a strong link between regional identity and secessionist attitudes in Catalonia (Muñoz and Tormos, 2015; Guinjoan and Rodon, 2016a), as well as in other regions-see, for instance, Costa-Font and Tremosa-Balcells (2008) for a study on the Basque country. In the specific case of Catalonia, Rodon and Guinjoan (2018) show that more than 90 percent of individuals that feel only Catalan (approximately 40 percent of the population) support secession, whereas the percentage for those who feel more Catalan than Spanish (about 30 percent of the population) is 65 percent. In contrast, among those individuals that feel only Spanish or more Spanish than Catalan (15 percent of the population), support for secession is below 5 percent. In between those individuals who feel exclusively or predominantly Catalan or Spanish, there are those who feel equally identified with the two entities, the so-called dual-identity individuals. Support for secession among individuals holding a dual identity (more than 40 percent of the population) is around 20 percent, despite it remarkably varies depending on the context in which the individual lives. Crucially, we know that, in Catalonia, the context in which an individual interacts shapes his or her preferences toward secession. Rodon and Guinjoan (2018) show that the effect of social networks is not the same for all identity groups. The most relevant change occurs among dual-identity individuals, whose probability to favor secession grows as the context in which they interact becomes more pro-secession. In contrast, the context is marginally relevant for the more Catalan than Spanish individuals, and irrelevant for those who feel exclusively Catalan or Spanish, and for those more Spanish than Catalan. The reason why the effect of context is stronger among dual-identity individuals than among the other identity groups stems from the fact that individuals in this group are more likely to be cross-pressured by both the pro- and anti-secession camps and, thus, can more easily opt for 
one side or the other depending on contextual circumstances. This behavior is different for individuals with predominantly or exclusive national or regional identities, as their identity strongly predetermines their stances toward independence, irrespective of where and with whom they interact-that is, the local contextual circumstances.

Thus, our expectation is that the effect of police interventions on the likelihood of participating in the referendum will be crucially shaped by an individual's identity. In a nutshell: we expect the predisposition to participate in the referendum to be considerably unaffected by police interventions among those individuals with exclusively and predominantly Catalan identities. Their strong stances on the issue of independence and their (favorable) predisposition to participate in the consultation are unlikely to be modified by police violent actions. Also, we expect that, when participation became impossible in the polling station where the individual wanted to vote (either because it was closed down by the police, or because of the fear of being beaten), an individual feeling predominantly Catalan was likely travel to a neighboring polling place to cast a ballot-and the opposite stands for individuals who feel predominantly Spanish, whose negative predisposition to participate in the referendum was unlikely to be modified as a result of the police actions during the referendum day.

We have, however, a different expectation for dual-identity individuals. Compared to exclusively and predominantly Catalan or Spanish individuals, their stances toward the referendum (and independence) are more ambivalent. Thus, we contend that they will be more elastic to police violence. In other words, if police interventions had an effect on political participation, both locally and in the neighboring areas, we should observe that dual-identity individuals are more likely to be mobilized than the rest.

From a behavioral point of view, if a police intervention had an effect on the likelihood of participating, we could also expect the timing of the decision to vote-whether the individual decided to vote before or during the referendum day-to be different across identity groups. Late vote deciders have been shown to lack partisan predispositions (Schmitt-Beck and Partheymüller, 2012), to be less interested in politics (Henderson and Hillygus, 2016), and to hold more ambivalent opinions (about candidates) - thus being more open to persuasion (Nir and Druckman, 2008). Hence, in the specific case of the 1 October referendum, late deciders may coincide with those individuals with more ambivalent stances toward the referendum, that is, dual-identity voters. Indeed, among exclusively and predominantly Catalan individuals, the decision to vote was likely taken before referendum day and, consequently, would have been unaffected by police interventions. The same should happen for exclusively and predominantly Spanish individuals and their decision to not vote in the referendum. In contrast, dual-identity individuals might have been more uncertain on whether to vote or not, with several individuals deciding it in the very same day of the referendum. A police intervention close to their place of residence might have tip the balance in favor of participating.

\section{Data and research design}

We use a two-stage research design. In the first part, we exploit the spatial distribution of police interventions to examine the effect of police actions on turnout at the municipality level. In the second stage, we employ a survey conducted a few days after the referendum that contains the exact geographical coordinates of each respondent's place of residence.

\subsection{Aggregate level analysis}

In the aggregate-level analysis, we utilize a newly-created dataset that contains information on police interventions across the 947 Catalan municipalities (our unit of analysis), as well as the level of participation during the day of the referendum and other relevant covariates. Our main outcome of interest is the percentage of voters who participated in the referendum in 
each municipality. ${ }^{4}$ Due to the implementation of a universal census system, in 16 percent of the municipalities turnout was higher than 100 percent. Following an outlier analysis (see section $\mathrm{E}$ in the online Appendix), we restrict the analysis to 938 municipalities. ${ }^{5}$

Our main explanatory variable captures whether the municipality experienced a police intervention. The information about the geographical distribution of police interventions has been extracted from www.catmemoria.cat website and Altesa (2017). We identified and computed the geographical coordinates of polling stations raided by the police. Figure 1 shows the spatial distribution of polling stations affected by police interventions. In total, police raided 117 polling stations, located in 56 different municipalities. Most raided municipalities experienced only one police intervention, except for Barcelona and the other three capitals of the Catalan provinces (Girona, Tarragona, and Lleida), which witnessed more than one.

In the empirical analysis, we not only employ a dummy distinguishing whether the municipality was "treated" with police violence, but also capture the type and intensity of police interventions using additional indicators. We distinguish between municipalities where the police did not intervene (reference category), those where the police intervened but there was no violence, and those where the police clashed violently with citizens who were protecting the polling stations. We also calculate the number of police officers sent to each polling station. Finally, we capture whether the police raids confiscated electoral material (i.e., ballot boxes, computers, or ballots).

In a subsequent step, we explore the spatial spillover dynamics triggered by police violence by analyzing whether the police crackdown in certain places mobilized or demobilized citizens living near the affected point. We first calculated the (log of the) distance between each municipality's centroid and the closest polling station raided by the police. We use a first- and second-order term of the distance to see whether turnout followed an inverted U-shape trajectory (or not) around municipalities affected by police interventions. Similarly, we create a dummy variable that distinguishes municipalities adjacent to affected municipalities and another dummy that identifies municipalities that fall within a $5 \mathrm{~km}$ or $10 \mathrm{~km}$ buffer-radius based on the geographic location of polling stations that witnessed police intervention.

We include several controls in the models. We control for the political affiliation of the municipality's Mayor. This categorical variable distinguishes pro-independence mayors and pro-unionist ones. Its inclusion aims at accounting for two different logics. On the one hand, pro-secessionist Mayors may have facilitated the celebration of the referendum, thus boosting participation. On the other, police might have directed their interventions toward municipalities with pro-independence mayors. We also control for the percentage of people born in other Autonomous Communities (AC); the percentage of support for secessionist parties in the 2015 elections; population density; the (log of the) total population; and the municipality's elevation. ${ }^{6}$

To check whether the spatial distribution of police interventions followed a quasi-random pattern, we conduct a placebo test. For doing so, we examine whether affected and unaffected municipalities behaved differently before the referendum. In other words, in the absence of a police action, the difference between municipalities that experienced a police intervention versus those that did not should be constant over time. Figure 2 visually shows that the parallel trends assumption is not violated. Indeed, affected and unaffected municipalities evolved similarly up

\footnotetext{
${ }^{4}$ Source: Generalitat de Catalunya. Available at premsa.gencat.cat (last accessed: 11 November 2019).

${ }^{5}$ The online Appendix shows the summary statistics as well as extra information on the referendum and the events of that day.

${ }^{6} \mathrm{~A}$ control for turnout at the municipality level in the 2015 regional elections accounting for the fact that some municipalities have a larger tendency to participate in regular elections than others, provides the same results. However, since the mobilization logic of a referendum deemed illegal by the Spanish institutions and an ordinary election is different, we excluded the variable from the analyses.
} 


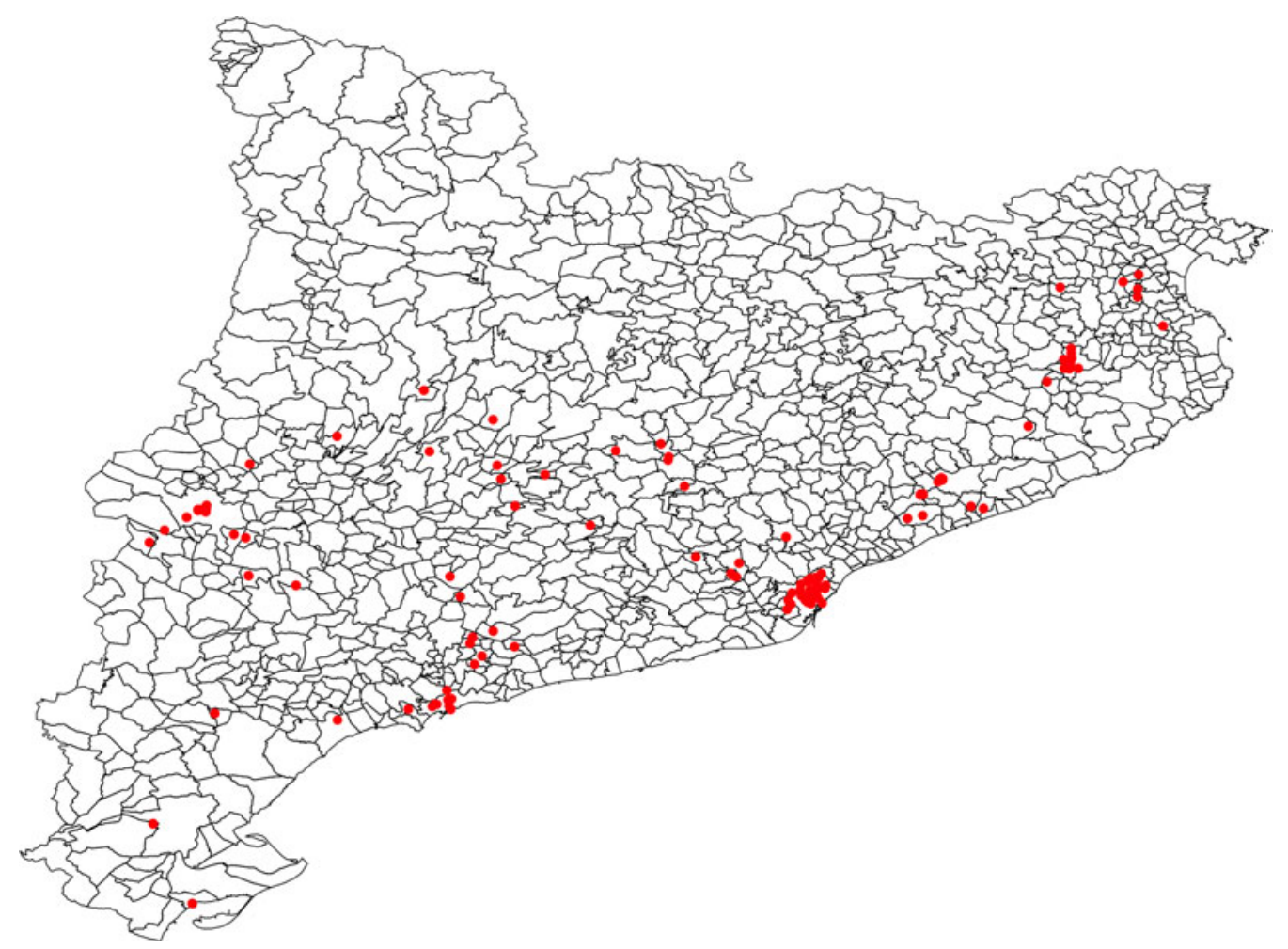

Figure 1. Spatial distribution of polling stations affected by police interventions.

until October 2017, when the police interventions took place. ${ }^{7}$ In substantive terms, we observe that in 2017 turnout is 25 percentage points lower in affected than in unaffected municipalities.

We complement the placebo test approach with several additional tests to check the spatial logic of police interventions. As we show in sections $\mathrm{C}$ and $\mathrm{D}$ in the online Appendix, police actions were not more likely to occur, for instance, in pro-secessionist areas or in densely populated municipalities. In addition, we carried out eight interviews to police officers, of different ranks, to examine the logic behind some police decisions. The interviewees confirm that each police squad was given a list of polling stations to go in the same morning of the referendum. Most importantly, as the interviewees acknowledged, police plans radically changed on the very morning of the referendum day as they were not expecting the implementation of the universal census, nor the large number of voters in front of the polling stations. As a result of this, each police squad radically changed its plans, which created an intervention pattern that was close to random (see online Appendix, section C). This interpretation of events by police officers is confirmed in our empirical tests, which show that affected and unaffected municipalities are very similar regarding some crucial covariates. Finally, previous literature on the effect of violence on political behavior has focused on the timing of such violence (Rasler, 1996). Accordingly, we coded the time of arrival of each police squad to each polling station. Although the data have some limitations (it is self-reported, there was no homogeneous criteria for reporting it, and there are a few missing), we confirm that turnout is not statistically different in those places where the police arrived earlier versus those where the police arrived later (see online Appendix, section $\mathrm{H}$ ).

\footnotetext{
${ }^{7}$ If anything, police interventions took place in municipalities where turnout was slightly lower, which goes against the expectation that the police targeted places with a priori higher level of mobilization.
} 


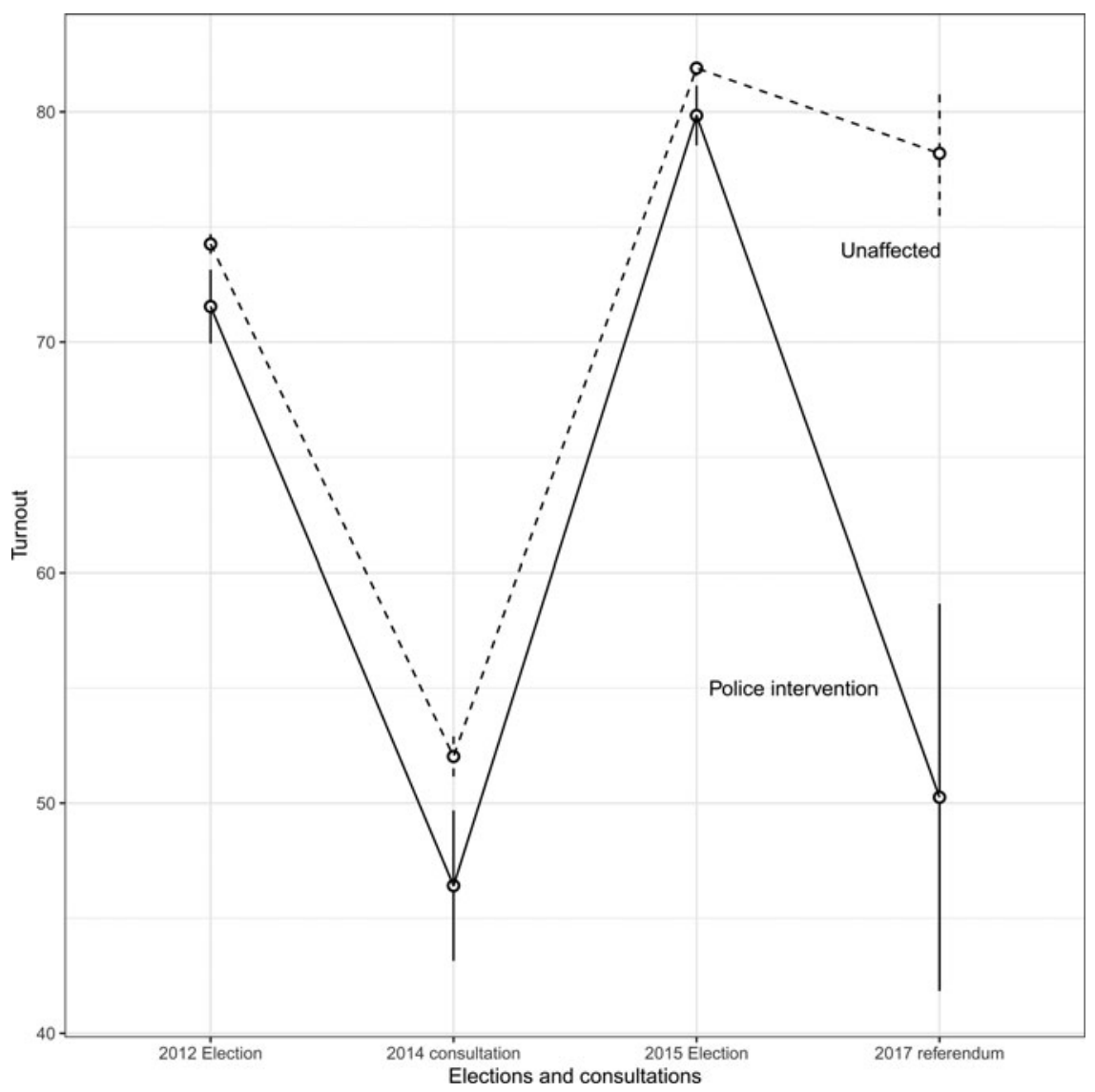

Figure 2. Turnout in municipalities with and without police intervention-parallel trends.

\subsection{Individual-level analysis}

In the individual-level part, we utilize a face-to-face survey conducted by the Centre d'Estudis d'Opinió (CEO) between 16 and 29 October 2017, just a few days after the referendum $(N=1$, 338). Our dependent variable is a dichotomous measure identifying whether the individual voted in the 1 October referendum. We then employ the exact location (latitude and longitude) of the respondent's residence in order to calculate the distance between polling stations that were raided by the police and his/her place of residence. Following the same strategy as in the aggregate-level analysis, we log transform the distance (in $\mathrm{km}$ ). We finally assign a value of 0 to all individuals whose municipality of residence experienced a police raid. The idea is that the distance to the polling station is irrelevant when an electoral college from the same municipality where an individual votes has been affected-even if we do not do it, results are virtually the same. We modulate the curvilinear effect by interacting the quadratic term of the (log of the) distance.

To see whether dual-identity individuals reacted differently to police interventions than predominantly and exclusively Catalan identity individuals, we interact the (log of the) distance to the nearest affected place with the national identity indicator. We rely on the most common measure of national identity employed by the literature on decentralization or secessionism: the Linz-Moreno question (Moreno, 1995; Guinjoan and Rodon, 2016b). This question asks respondents to choose a single identity from a range of five categories: "I feel only Spanish," "I feel more 
Spanish than Catalan," "I feel equally Catalan and Spanish" (dual-identity group), "I feel more Catalan than Spanish," and "I feel only Catalan." We recoded the exclusively and predominantly Spanish individuals into a single category due to the low number of individuals in these two groups. ${ }^{8}$ Additionally, to capture the timing when an individual decided to vote in the referendum, we use a dummy variable that identifies whether an individual took the decision to vote before the 1 October or during the same day.

Finally, all our individual-level models include a series of conventional controls: recall vote in the last Catalan parliamentary election (a political party in favor of secession, against secession, ambiguous or abstention), a respondent's place of birth (born in Catalonia versus born outside Catalonia), age, gender, education, the (log of the) population in 2017, and a dummy variable for Barcelona.

\section{Results: aggregate-level analysis}

\subsection{The effects of police intervention}

Did police interventions during the Catalan independence referendum day depress or increase turnout? Results show that, regardless of the indicator employed, those municipalities that witnessed a police presence reported a significantly lower turnout than the rest.

Figure 3 plots the predicted turnout as a function of the different indicators capturing police actions. The top-left figure shows that turnout in places that witnessed a police intervention was 15 percentage points lower compared to places where the police did not intervene. The top-right figure shows that the sole presence of the police had a negative effect on turnout, regardless of whether the intervention ended in violence. Municipalities that witnessed a non-violent police intervention had a turnout approximately 12 percentage points lower than places with no police intervention. Interestingly, it is approximately the same effect compared to places that witnessed a violent police action. The bottom-left figure confirms that the intensity of a police action had a negative effect on electoral participation. Similarly, the bottom-right figure shows that in places where the police stopped the consultation by confiscating electoral material, turnout was 25 percent points lower than in no intervened municipalities.

Next, we explore whether police interventions encouraged mobilization in surrounding areas (Figure 4). The top-left graph shows the predicted turnout rate in municipalities geographically adjacent to raided municipalities. The effect is positive: municipalities contiguous to places where the police intervened had a higher turnout than the rest. The top-right panel plots the predicted turnout in municipalities that fall within a $5 \mathrm{~km}$ or $10 \mathrm{~km}$ radius of targeted locations and the bottom graph shows the curvilinear relationship between the (log of the) distance between the municipality's centroid and the nearest polling station raided by the police. Both graphs show that turnout is low in places directly affected by police interventions, that it gradually increases as we move away from them-reaching its peak at approximately $2.25 \log (\mathrm{km})$ points from the raided electoral college (around $10 \mathrm{~km}$ ) - , and slightly decreases again as we move even further away-yet still being much larger than the one observed in attacked municipalities.

\section{Individual-level analysis}

\subsection{The heterogeneous impact of police interventions}

As we have shown, police intervention on the day of the referendum depressed political participation locally but increased it in the immediate surrounding areas. Although the results are robust across different specifications, one important concern remains due to the aggregate nature of the data. Catalan municipalities are small, but some of them have significant internal

\footnotetext{
${ }^{8}$ Police intervention did not heterogeneously affect the change in the configuration of identities before and after the referendum when comparing raided and non-raided municipalities. See online Appendix, section K.
} 

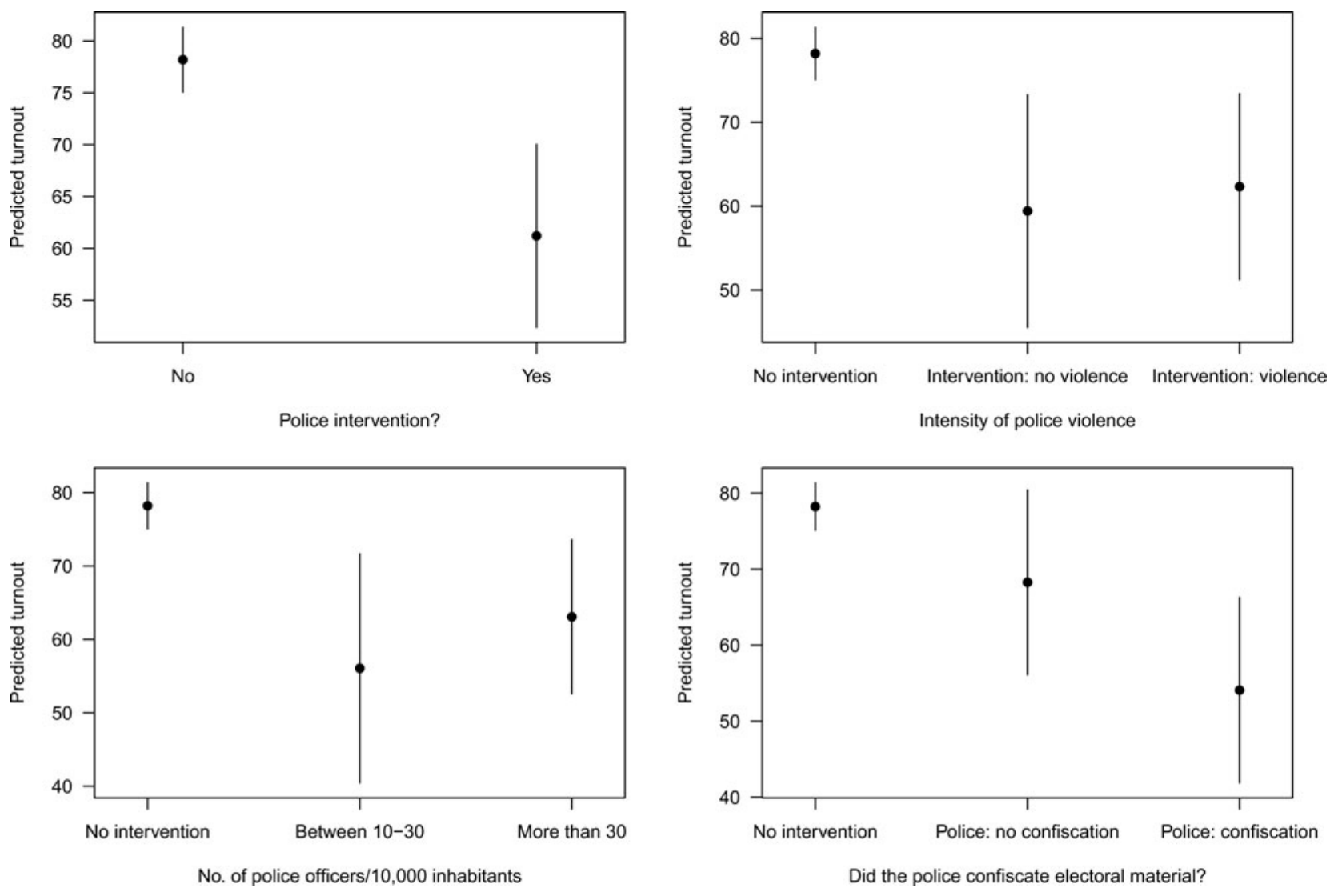

Figure 3. The effect of police interventions on turnout. 

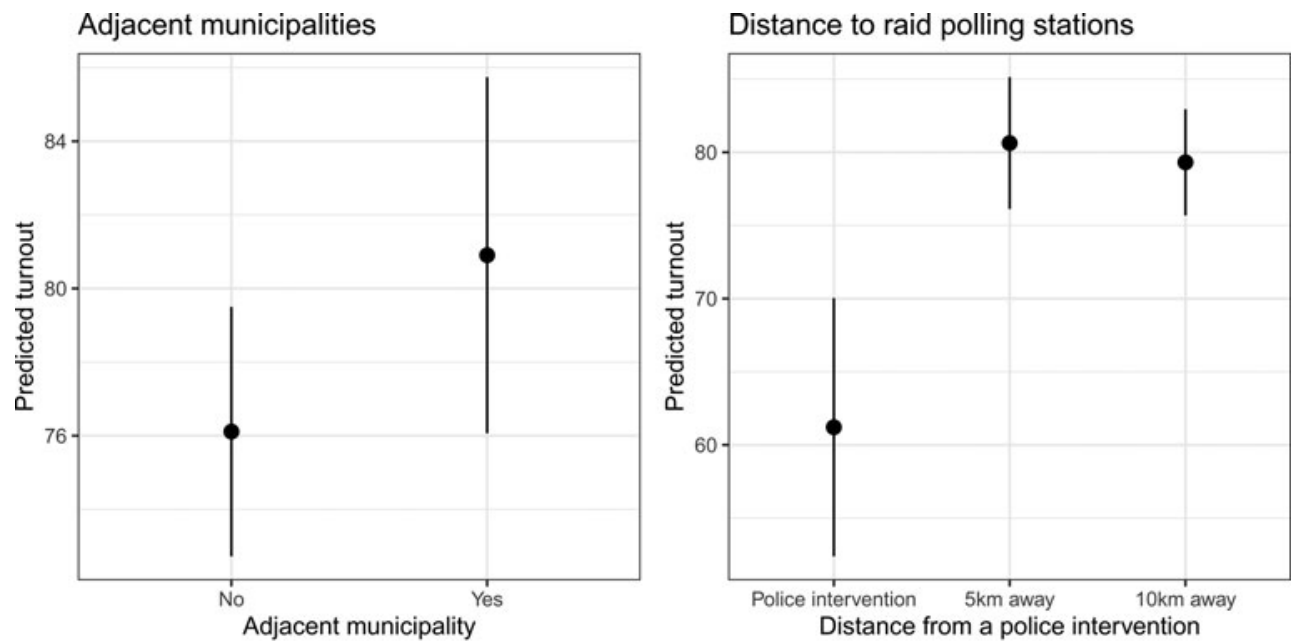

Distance to raided polling stations (Curvilinear relationship)

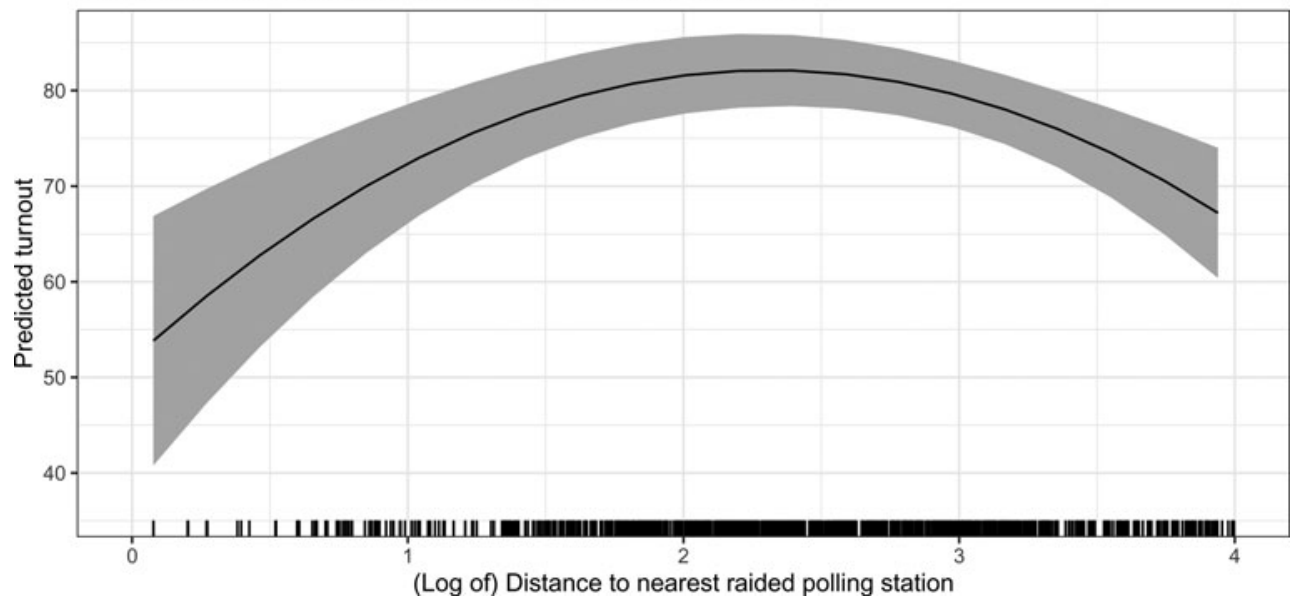

Figure 4. Predicted turnout around targeted municipalities.

heterogeneity, which is removed when we use an aggregate-level percentage. We circumvent this limitation by using a survey conducted a few days after the referendum. These data also allow us to dig deeper into who was (de)mobilized as a result of clashes with the police. Most importantly, it will help us understand whether people from the raided municipalities actually went to vote or not. In a nutshell: in the aggregate-level analysis, a curvilinear relationship entails that individuals in municipalities close to towns that witnessed a police action turned out to vote to a larger degree. This could have been for two different reasons. First, people in surrounding municipalities who were uncertain about voting and eventually decided to participate due to police intervention; second, people from affected municipalities who went to neighboring towns to vote.

However, in the individual-level analysis, by asking whether individuals eventually voted, we are discarding the second of the options: a no vote answer is telling us that the individual did participate neither in his/her municipality nor in a close town-note that the survey did not ask whether the individual voted in his/her municipality, but rather whether he/she voted. Hence, in this section of the analysis, a curvilinear relationship in the probability to vote across the different values of the (log) distance to the nearest raid polling station means two different 
things. First, that people from municipalities that witnessed a police intervention decided not to vote, that is, they were demobilized due to police violence. Second, that people from neighboring municipalities decided to participate, that is, they were activated by police intervention. Critically, this evidence is irrespective of the fact that people from attacked municipalities voted in neighboring towns.

The top panel in Figure 5 shows the predicted turnout across the different values of the (log) distance to the nearest raided polling station. Results show that the predicted probability of voting in the 1 October referendum increases as we move away from a raided area. In particular, in municipalities $2.2 \mathrm{log}$ points away from an affected municipality (around $10 \mathrm{~km}$ ), the difference in participation reaches its highest value, 6.2 percent points-at values higher than $2.75 \log$ points (more than $15 \mathrm{~km}$ ) differences cease to be statistically significant. This evidence is highly consistent with the aggregate-level analysis, where the peaking point in the turnout gap also corresponds to municipalities placed $10 \mathrm{~km}$ away from an affected municipality. In these places the participation rate increased by 25 percent points. All in all, these figures show that around 25 percent of the total impact of police interventions on turnout ( 6 percent points out of 25) may be due to the activation of new voters-as accounted in this individual-level analysis-, whereas the remaining 75 percent may be explained by individuals living in raided municipalities traveling to neighboring towns.

Next, we assess the existence of heterogeneous effects on participation across identity groups. As noted in the theory section, we expect dual-identity individuals, who have weaker stances on the issue of secession, to be more malleable (elastic) to contextual circumstances and hence, in our case, to police interventions. As shown in the bottom panel in Figure 5, respondents who feel only Catalan and more Catalan than Spanish were more likely to participate in the referendum than the rest. Crucially, the figure also shows that the curvilinear effect of police interventions affected individuals with exclusive Catalan identities, predominantly Catalan identities, and dual-identity individuals. In contrast, and in line with our expectations, differences among predominantly and exclusively Spanish individuals living in affected and non-affected municipalities are not statistically significant across the different values of the $\mathrm{x}$ axis.

Among dual-identity individuals, the likelihood of participating in the referendum, which remains relatively low in the places where the police intervened, increases in the surrounding areas. Approximately $1 \mathrm{log}$ point away from an attacked point (around $3 \mathrm{~km}$ ), the likelihood that a dual-identity individual votes increases by 7 percent points (differences statistically significant at the 95 percent level), whereas the peaking point corresponds to 2.8 log points from a raided town $(16 \mathrm{~km})$, where the turnout gap increases by 12 points $(\mathrm{p}<0.01)$. Finally, results also show that the turnout gap between the only and predominantly Catalan identity individuals, on the one hand, and dual-identity individuals, on the other, closes as the distance between the respondent's place of residence and the nearest polling station raided by the police increases. In fact, at $4 \log$ points away from a raided municipality $(55 \mathrm{~km})$, the differences between dual-identity individuals and more Catalan than Spanish individuals are only statistically significant at the 10 percent level.

\subsection{Who decided to participate during the referendum day?}

In this last subsection, we aim at digging deeper on the dynamics discussed above by examining the moment in which an individual decided he/she would vote in the referendum. If people living near municipalities that were affected by a police intervention decided to participate in the referendum in the same day of the vote, this will provide us with further evidence that they changed their behavior as a result of police actions. Most importantly, a voter's national identity should be crucial in shaping his/her decision to vote. We once again expect that dual-identity individuals were more likely to decide to participate during the referendum day. If this is the case, we will have additional evidence that some people became angry and hence decided to participate 

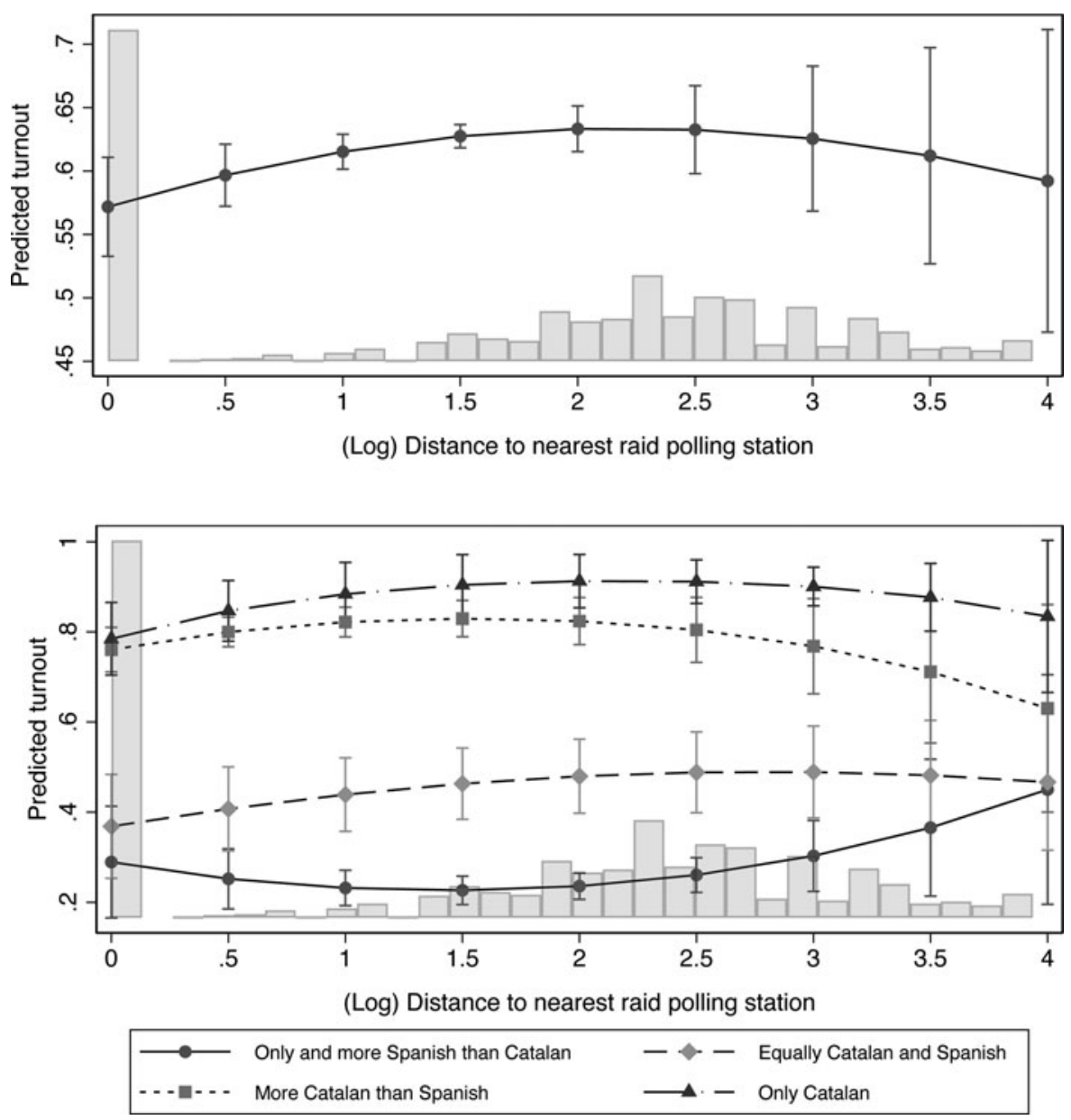

Figure 5. The effect of police intervention on turnout (individual-level analysis).

when they were exposed to police brutality, a pattern consistent with the idea that some people participated in the referendum as a way to protest or to engage in a civil disobedience action.

To address this question, we run a logistic regression model using an outcome the recall decision to vote $(1=R$ decided to participate in the referendum day; $0=R$ decided before the referendum day). The top left panel in Figure 6 displays the predicted probability of deciding to participate in the referendum on the same referendum day in the different type of municipalities: those municipalities affected by police intervention, those unaffected municipalities close to raided ones, and unaffected municipalities far away from a raided one. ${ }^{9}$ Figure 6 shows a curvilinear pattern between the decision to participate and the type of municipality. As can be seen, individuals living in municipalities near a police intervention are more likely to report that they decided to participate in the same referendum day. Who decided to participate on the same day because of the police actions? The top right panel in Figure 6 shows strong support for the idea that dual-identity individuals decided, to a larger extent, their participation in the referendum during the same day. Among exclusively Catalan (Spanish) individuals, the likelihood of having been

\footnotetext{
${ }^{9}$ Due to the low number of observations, we cannot use the (log) of the distance to the exact location of a police intervention. Hence, we have split the unaffected municipalities in two equally-sized groups. Also, the model cannot estimate the effects for exclusively and predominantly Spanish individuals due to the low number of observations in each group.
} 

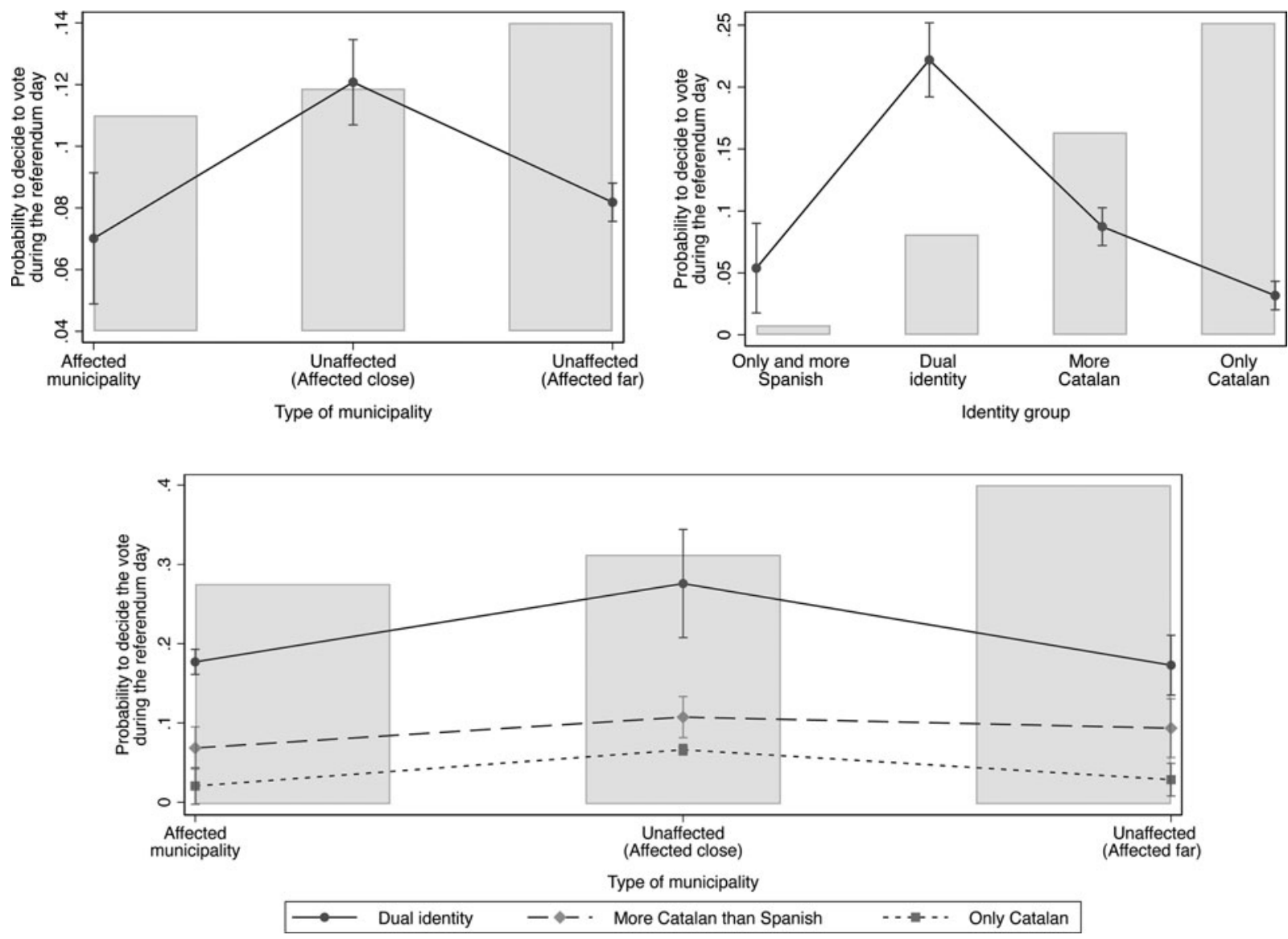

Figure 6. The effect of police interventions on whether $R$ decided to vote the same referendum day or before). 
activated during the referendum day is 3 and 5 percent, respectively (differences between the two groups are not statistically significant). The percentage increases until 9 percent for those who feel more Catalan than Spanish, and up to 22 percent for the dual-identity individuals. Overall, these results confirm what we anticipated: nationally ambivalent individuals were more likely to be mobilized during the day of referendum. Also, it shows that, despite to a much lower degree, predominantly Catalan individuals were also considerably activated during the 1 October referendum.

Finally, why did dual-identity individuals (and, to a lower extent, more Catalan than Spanish ones) decide their participation in the referendum much later than the rest? It could be that the decision was ultimately shaped by police interventions, but it could also be that individuals in the dual identity group were more ambivalent about the issue of independence and, therefore, undecided on whether to participate in the referendum until the same day. Despite we cannot directly address the reasons why these voters ended up casting a vote, we can indirectly explore them by examining dual-identity individual's decision to participate in the different type of municipalities. Our expectation is that, since police interventions had a positive spatial spillover effect on the decision to vote, dual-identity individuals living in surrounding municipalities should have been more likely to have decided to participate during the same referendum day. A similar effect may be expected for predominantly Catalan individuals, but not for the exclusively ones.

Results in bottom panel in Figure 6 show that dual-identity individuals living in unaffected municipalities close to a raided area were the ones more likely to decide their vote on the same day of the referendum. Differences are statistically significant when compared to dual-identity individuals living in raided municipalities, and in municipalities that did not witness a police action and were located far away from any police intervention. This evidence is consistent with the fact that police interventions triggered a positive impact on mobilization in adjacent municipalities, when compared to affected towns and spatially distant non-affected towns. Results for individuals that feel more Catalan than Spanish show that police actions mobilized them, regardless of whether the municipality was close or far away from an affected town. Finally, and perhaps most surprisingly, we also see that despite most exclusively Catalan individuals had decided that they would participate in the referendum early on in time, a few undecided ones did not do so until they were exposed to the police action in a nearby municipality.

\section{Conclusion and discussion}

Our empirical contribution advances research in several ways. First, although some studies have found that police actions trigger mobilization, others conclude it depresses it. Our paper shows that police interventions had a negative effect on political participation locally, but they induced positive spatial spillover effects on the surrounding areas. Compared to previous studies, our study not only offers additional evidence on how voters react to violent (police) actions in modern democracies, but it also adds to the scarce research looking into the spatial dynamics of violence and mobilization. More concretely, we show that there is a curvilinear spatial relationship between violence and political mobilization.

Second, on a related point, we show that voter mobility to neighboring towns is not the only reason that accounts for this spatial curvilinear pattern. According to our results from the aggregate- and the individual-level data analysis, we have estimated that around 25 percent of the total impact of police interventions on turnout may be due to the activation of new voters, whereas the remaining 75 percent may be explained by individuals living in municipalities raided by the police traveling to neighboring towns. Among the mobilized voters near police interventions, there was a large proportion of undecided or ambivalent voters-those who had a dual identity. Our interpretation of this pattern is that some dual-identity individuals, for whom the probability to participate in the referendum, or to travel to another town to vote, was low, got angry and subsequently mobilized after they saw the police violence in neighboring towns. In this sense, our results are in line with Aytaç et al. (2017, 13-14), who show that people 
who witnessed violence and joined a Turkish protest in 2013 "expressed a sense of persistent and increasing irritation rather than a drastic shift in political perceptions or opinions." Aligned with this narrative, some dual-identity individuals ended up participating in the referendum, which does not probably imply they changed their mind on the independence debate, but they rather wanted to protest against police actions.

Finally, and more in general, our study focuses on a case that is located between an institutional consultation and an act of civil disobedience or protest. In fact, one could see this case as a protest framed in a voting context. In this sense, our findings shed light on how civil resistance operates when police intervenes and help us understand the reaction of those individuals less supportive of protests in the context of police overreaction. Despite referendums considered illegal are uncommon, protests that end up in violence are not. According to data from Kriesi et al. (2020), a substantial amount of protests in several European countries during the 20002015 period were confrontational or violent. Thus, the findings on our paper can inform us about the consequences of such events. Future research can also examine whether police interventions on these protests have an effect on basic democratic attitudes (trust, satisfaction with democracy) or even on voting patterns in subsequent elections.

More in general, we encourage future scholars to dig deeper on the contagion effect of violence (Siegel, 2011), both with a spatial and a social network perspective. In this paper, we have offered what we think is an interesting avenue forward, namely how certain events drive the spatial diffusion of political mobilization. With the appropriate dataset, one can take a step further and examine how dense versus loose social networks effectively transmit the information or the conditions under which the spatial contagion is stronger/weaker.

Finally, future research might also address under what conditions state violence triggers "solidarity" among those groups who are less sympathetic to protesters or to the political cause against which police violence is directed. Politically ambivalent voters in Catalonia are usually equated to dual-identity individuals, but ambiguous voters can take different profiles in other contexts. Future research can examine how politically undecided individuals react to tense political circumstances, particularly in ideologically-polarized societies or in contexts in which the voice of the minority is constantly silenced by the majority via legal or repressive means.

Supplementary material. The supplementary material for this article can be found at https://doi.org/10.1017/psrm.2020.48.

\section{References}

Aidt TS, Leon G and Satchell M (2017) The Social Dynamics of Collective Action: Evidence from the Captain Swing Riots, 1830-31. Working paper.

Altesa C (2017) “Actuacions policials. L'1 d'octubre en xifres.” https://catmemoria.cat/wp-content/uploads/2017/10/1-octubre-Actuacions-Policials-en-xifres.pdf.

Aytaç SE, Schiumerini L and Stokes S (2017) Why do people join backlash protests? Lessons from Turkey. Journal of Conflict Resolution 62(6), 1205-1228.

Baudains P, Johnson SD and Braithwaite AM (2013) Geographic patterns of diffusion in the 2011 London riots. Applied Geography 45, 211-219.

Blattman C (2009) From violence to voting: war and political participation in Uganda. American Political Science Review 103 (2), 231-247.

Chenoweth E and Stephan MJ (2011) Why civil resistance works: The strategic logic of nonviolent conflict. New York: Columbia University Press.

Condra LN, Long JD, Shaver AC and Wright AL (2018) The logic of insurgent electoral violence. American Economic Review 108(11), 3199-3231.

Costa-Font J and Tremosa-Balcells R (2008) Support for state opting out and stateless national identity in the Basque Country. The Journal of Socio-Economics 37(6), 2464-2477.

Coupe T and Obrizan M (2016) Violence and political outcomes in Ukraine-evidence from Sloviansk and Kramatorsk. Journal of Comparative Economics 44(1), 201-212.

DeNardo J (2014) Power in numbers: The political strategy of protest and rebellion. New Jersey: Princeton University Press.

Desmond M, Papachristos AV and Kirk DS (2016) Police violence and citizen crime reporting in the Black community. American Sociological Review 81(5), 857-876. 
Earl J (2011) Political repression: iron fists, velvet gloves, and diffuse control. Annual Review of Sociology 37(1), 261-284.

Enos RD, Kaufman AR and Sands ML (2019) Can violent protest change local policy support? Evidence from the aftermath of the 1992 Los Angeles riot. American Political Science Review 113(4), 1012-1028.

Francisco RA (1995) The relationship between coercion and protest: an empirical evaluation in three coercive states. Journal of Conflict Resolution 39(2), 263-282.

Granovetter M (1978) Threshold models of collective behavior. American Journal of Sociology 83(6), 1420-1443.

Guinjoan M and Rodon T (2016a) Catalonia at the Crossroads: Analysis of the Increasing Support for Secession. In Cuadras-Morato X (ed.), Chapter 2 in Catalonia: A New Independent State in Europe? A debate over secession within the European Union. New York: Routledge, pp. 20-61.

Guinjoan M and Rodon T (2016b) A scrutiny of the Linz-Moreno question. Publius: The Journal of Federalism 46(1), 128142.

Gurr TR (1969) Why Men Rebel. Princeton University Press, Princeton.

Henderson M and Hillygus DS (2016) Changing the clock: the role of campaigns in the timing of vote decision. Public Opinion Quarterly 80(3), 761-770.

Hess D and Martin B (2006) Backfire, repression, and the theory of transformative events. Mobilization 11, $249-267$.

Jones DB, Troesken W and Walsh R (2017) Political participation in a violent society: the impact of lynching on voter turnout in the post-Reconstruction South. Journal of Development Economics 129, 29-46.

Kriesi H, Wüest B, Lorenzini J, Makarov P, Enggist M, Rothenhäusler K, Kurer T, Häusermann S, Wangen P, Altiparmakis A, Borbáth E, Bremer B, Gessler T, Hunger S, Hutter S, Schulte-Cloos J and Wang C (2020) PolDem-Protest Dataset 30 European Countries, Version 1.

Laniyonu A (2019) The political consequences of policing: evidence from New York City. Political Behavior 41(2), 527-558.

Lerman AE and Weaver V (2014) Staying out of sight? Concentrated policing and local political action. The Annals of the American Academy of Political and Social Science 651(1), 202-219.

Ley S (2017) To vote or not to vote: how criminal violence shapes electoral participation. Journal of Conflict Resolution 62, 128.

Lichbach MI (1987) Deterrence or escalation?: The puzzle of aggregate studies of repression and dissent. Journal of Conflict Resolution 31(2), 266-297.

Lichbach MI and Gurr TR (1981) The conflict process: a formal model. Journal of Conflict Resolution 25(1), 3-29.

Linden A and Klandermans B (2006) Stigmatization and repression of extreme-right activism in the Netherlands. Mobilization: An International Quarterly 11(2), 213-228.

Martin B (2005) The beating of Rodney King: the dynamics of backfire. Critical Criminology 13(3), 307-326.

Moreno L (1995) Multiple ethnoterritorial concurrence in Spain. Nationalism and Ethnic Politics 1, 11-32.

Muller EN and Weede E (1990) Cross-national variation in political violence: a rational action approach. The Journal of Conflict Resolution 34(4), 624-651.

Muñoz J and Anduiza E (2019) If a fight starts, watch the crowd. The effect of violence on popular support for social movements. Journal of Peace Research 56(4), 485-498.

Muñoz J and Tormos R (2015) Economic expectations and support for secession in Catalonia: between causality and rationalization. European Political Science Review 7(2), 315-341.

Nir L and Druckman JN (2008) Campaign mixed-message flows and timing of vote decision. International Journal of Public Opinion Research 20(3), 326-346.

Rasler K (1996) Concessions, repression, and political protest in the Iranian revolution. American Sociological Review 61(1), 132-152.

Rodon T and Guinjoan M (2018) When the context matters: identity, secession and the spatial dimension in Catalonia. Political Geography 63, 75-87.

Salamon LM and Van Evera S (1973) Fear, apathy, and discrimination: a test of three explanations of political participation. American Political Science Review 67(4), 1288-1306.

Schmitt-Beck R and Partheymüller J (2012) Why voters decide late: a simultaneous test of old and new hypotheses at the 2005 and 2009 German federal elections. German Politics 21(3), 299-316.

Siegel DA (2011) When does repression work? Collective action in social networks. The Journal of Politics 73(4), 993-1010.

Valentino NA, Brader T, Groenendyk EW, Gregorowicz K and Hutchings VL (2011) Election night's alright for fighting: the role of emotions in political participation. Journal of Politics 73(1), 156-170.

Wilkinson SI (2006) Votes and violence: electoral competition and ethnic riots in India. Cambridge University Press, Cambridge.

Cite this article: Rodon T, Guinjoan M (2022). Beaten ballots: political participation dynamics amidst police interventions. Political Science Research and Methods 10, 153-170. https://doi.org/10.1017/psrm.2020.48 